\title{
Male reproductive health disorders among Aboriginal and Torres Strait Islander men: a hidden problem?
}

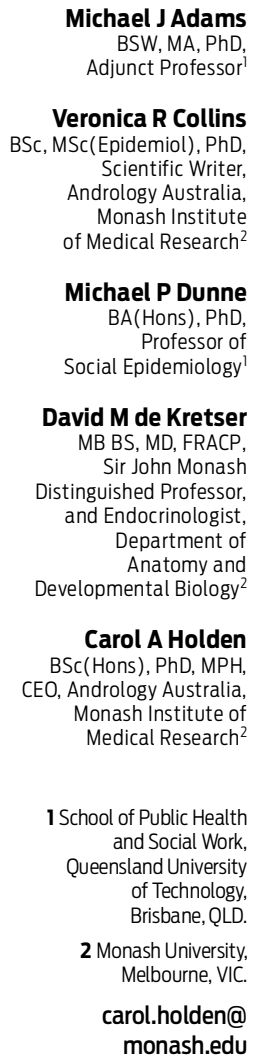

MJA 2013; 198: 33-38 doi: $10.5694 / \mathrm{mjal} 2.10490$ trong associations between chronic disease and erectile dysfunction (ED) highlight the need for male health assessments to include reproductive health, irrespective of age, culture or sexual relationship. ${ }^{1}$ Within 1 year from a first episode of ED in men aged 55 years or over, $2 \%$ were reported to have a major stroke or myocardial infarction, with this proportion rising to $11 \%$ by 5 years. ${ }^{2}$ Despite high rates and concern about ED reported by middleaged or older Australian men, the rate of discussion and treatment of reproductive disorders in medical consultations was much lower. ${ }^{3}$ Barriers exist for men seeking help for reproductive health disorders, especially for some cultural groups and geographical locations. ${ }^{4}$ In regional and remote locations, there is limited choice of care providers, and concerns about privacy may impact on seeking help for ED. ${ }^{5}$ As Aboriginal and Torres Strait Islander men have high rates of cardiovascular disease and diabetes, ${ }^{6}$ ED is likely to be common. ${ }^{7}$ However, there are no published empirical reports measuring the extent of the problem in Aboriginal and Torres Strait Islander men.

The sensitive nature of reproductive health disorders may be of particular concern for Aboriginal and Torres Strait Islander men, especially in remote communities, where these matters are traditionally seen as taboo, requiring culturally appropriate and gender-specific services. ${ }^{7}$ This study was undertaken to improve understanding of reproductive health problems in Aboriginal and Torres Strait Islander men, as early detection may be important in identifying chronic disease. ${ }^{8}$ To maximise trust and disclosure in a non-clinical setting, the lead researcher and interviewers were Indigenous men with links to the communities. In this article, we report on help-seeking behaviours, the prevalence and possible determinants of $\mathrm{ED}$, and testing for

\begin{abstract}
Objective: To better understand help-seeking behaviours and reproductive health disorders among Aboriginal and Torres Strait Islander men.

Design, setting and participants: A cross-sectional mixed-methods study conducted from 1 May 2004 to 30 April 2005 of 293 Aboriginal and Torres Strait Islander men aged 18 years and over from urban, rural and remote communities in the Northern Territory and Queensland.
\end{abstract}

Main outcome measures: Subscale of the International Index of Erectile Function, self-reported help-seeking behaviours for erectile dysfunction (ED) and prostate disease, thematic analysis of semi-structured interviews and focus groups.

Results: The prevalence of moderate-to-severe ED increased across age groups, from about $10 \%$ in younger men (under 35 years) to $28 \%$ in men aged 55-74 years. Moderate-to-severe ED was strongly associated with reporting a chronic condition (odds ratio [OR], 3.67) and residing in a remote area (OR, 2.94). Aboriginal and Torres Strait Islander men aged 40-59 years showed similar low levels of help-seeking behaviours compared with nonIndigenous men from a comparable population-based study. About half of the men with ED saw a doctor or received treatment for ED in each population. While prostate cancer rates were low in both studies, testing for prostate problems was less frequent in Aboriginal and Torres Strait Islander men (11.4\%) than in non-Indigenous men $(34.1 \%, P<0.001)$, despite similar levels of concern about prostate cancer. Barriers to help-seeking included shame, culturally inappropriate services and lack of awareness.

Conclusion: This study, the first to investigate reproductive health of Aboriginal and Torres Strait Islander men, found low levels of help-seeking behaviours for reproductive health disorders, with implications for missing a predictor of chronic disease and late diagnosis of prostate disease.

prostate disease in Aboriginal and Torres Strait Islander men.

\section{Methods}

Researching Aboriginal and Torres Strait Islander health requires the intertwining of ethical concerns with appropriate methods. ${ }^{9}$ Most researchers have collected data on reproductive health through telephone interviews or mailed questionnaires. ${ }^{3,10-12}$ This study incorporated the specific cultural understandings and needs of Aboriginal and Torres Strait Islander men and the sensitivities of the topic using a different approach.

In-depth consultation and negotiation with the target communities ensured that they understood the research, were comfortable with the topic of interest and were willing to participate. The role of the primary author (MJA), an Aboriginal man with experience and knowledge of Aboriginal customs and culture (an "insider") as well as an academic researcher (an "outsider"), was pivotal to the conduct of the study. Local Aboriginal and Torres Strait Islander people were engaged as facilitators to provide cultural, historical, generational and gender perspectives as, regardless of insider/outsider status, a lack of respect for cultural, political and social structures of communities can impede research. ${ }^{13}$ The study had the support of the Aboriginal community-controlled health services and governing councils and elders of the communities, with approval from the Queensland University of Technology Human Research Ethics Committee.

\section{Study design}

The study involved a quantitative cross-sectional survey and qualitative interviews and focus groups. The qualitative component aimed to gain a deeper understanding of men's lived experiences of reproductive health issues and to identify solutions from 


\begin{tabular}{|c|c|}
\hline \multicolumn{2}{|c|}{$\begin{array}{l}\text { Demographic characteristics of } 293 \\
\text { Aboriginal and Torres Strait } \\
\text { Islander men from urban, rural and } \\
\text { remote communities in the } \\
\text { Northern Territory and Queensland }\end{array}$} \\
\hline Characteristic & Participants \\
\hline \multicolumn{2}{|l|}{ Location } \\
\hline Urban & $185(63.1 \%)$ \\
\hline Rural & 41 (14.0\%) \\
\hline Remote & $67(22.9 \%)$ \\
\hline \multicolumn{2}{|l|}{ Ancestry } \\
\hline Aboriginal & $241(82.3 \%)$ \\
\hline Torres Strait Islander & 17 (5.8\%) \\
\hline Both & $35(11.9 \%)$ \\
\hline \multicolumn{2}{|l|}{ Age group (years) } \\
\hline $18-24$ & $33(11.3 \%)$ \\
\hline $25-34$ & $88(30.0 \%)$ \\
\hline $35-44$ & $87(29.7 \%)$ \\
\hline $45-54$ & $56(19.1 \%)$ \\
\hline 55-74 & 29 (9.9\%) \\
\hline \multicolumn{2}{|l|}{ Education level } \\
\hline None/primary & $45(15.4 \%)$ \\
\hline Secondary school & $168(57.3 \%)$ \\
\hline Tertiary & $80(27.3 \%)$ \\
\hline \multicolumn{2}{|l|}{ Marital status } \\
\hline Married/partnered & $177(60.4 \%)$ \\
\hline Separated/widowed & $31(10.6 \%)$ \\
\hline Never married & 85 (29.0\%) \\
\hline \multicolumn{2}{|l|}{ Employment status } \\
\hline Employed & $178(60.8 \%)$ \\
\hline Unemployed & $68(23.2 \%)$ \\
\hline Pensioner & $37(12.6 \%)$ \\
\hline Student & $10(3.4 \%)$ \\
\hline \multicolumn{2}{|l|}{ Fathered children?* } \\
\hline Yes & $99 / 292(68.2 \%)$ \\
\hline
\end{tabular}

* One man did not answer this question and is not included in the results.

an Aboriginal and Torres Strait Islander perspective.

\section{Study sample}

Focus groups of 20 participants (three men's groups and one women's group) were held in communities in Darwin, the Tiwi Islands and Brisbane. Face-to-face interviews were done with a further 18 men to encourage personal perspectives not easily revealed in focus groups. Participants were aged between 29 years and 45 years. The focus groups were akin to a "yarning circle" where the participants contributed their thoughts on engaging men about sexual and reproductive health issues. Some participants in the focus groups and interviews also participated in the questionnaire at a later date.

We used quota sampling in the questionnaire study, as there was no

2 Characteristics, health behaviours and conditions by age group in 293 Aboriginal and Torres Strait Islander men from urban, rural and remote communities in the Northern Territory and Queensland

\begin{tabular}{|c|c|c|c|}
\hline & $\begin{array}{c}18-44 \text { years } \\
\left(n=208^{*}\right)\end{array}$ & $\begin{array}{c}\text { 45-74 years } \\
\left(n=85^{*}\right)\end{array}$ & $P$ \\
\hline Body mass index $(\mathrm{BMI})^{\dagger}$ & $(n=200)$ & $(n=84)$ & \\
\hline Normal weight $(\mathrm{BMI}<25.0$ kg/m²) & $57 / 200(28.5 \%)$ & $8 / 84(9.5 \%)$ & 0.002 \\
\hline Overweight (BMI $25.0-29.9$ kg/m²) & $74 / 200(37 \%)$ & $39 / 84(46.4 \%)$ & \\
\hline Obese $\left(\mathrm{BMI} \geqslant 30.0 \mathrm{~kg} / \mathrm{m}^{2}\right)$ & $69 / 200(34.5 \%)$ & $37 / 84(44.0 \%)$ & \\
\hline \multicolumn{4}{|l|}{ Smoking } \\
\hline Never/given up & $86(41.3 \%)$ & $56(65.9 \%)$ & $<0.001$ \\
\hline Occasionally & $36(17.3 \%)$ & $5(5.9 \%)$ & \\
\hline Regularly & $86(41.3 \%)$ & $24(28.2 \%)$ & \\
\hline $\begin{array}{l}\text { Number of cigarettes per day (among } \\
\text { occasional and regular smokers) }\end{array}$ & $(n=122)$ & $(n=29)$ & \\
\hline $1-10$ & 45/122 (36.9\%) & $8 / 29(27.6 \%)$ & 0.21 \\
\hline $11-20$ & $50 / 122(41.0 \%)$ & $10 / 29(34.5 \%)$ & \\
\hline$>20$ & $27 / 122(22.1 \%)$ & $11 / 29$ (37.9\%) & \\
\hline \multicolumn{4}{|l|}{ Frequency of drinking alcohol } \\
\hline Never & $34(16.3 \%)$ & $28(32.9 \%)$ & $<0.001$ \\
\hline Less than or once per week & $110(52.9 \%)$ & $23(27.1 \%)$ & \\
\hline More than once per week & $64(30.8 \%)$ & $34(40 \%)$ & \\
\hline $\begin{array}{l}\text { Number of drinks per day (typical } \\
\text { number of drinks per day among } \\
\text { occasional and regular drinkers) }{ }^{\ddagger}\end{array}$ & $(n=173)$ & $(n=57)$ & \\
\hline $1-4$ & $37 / 173(21.4 \%)$ & $17 / 57(29.8 \%)$ & 0.21 \\
\hline $5-9$ & $70 / 173(40.5 \%)$ & $25 / 57(43.9 \%)$ & \\
\hline$>9$ & $66 / 173(38.2 \%)$ & $15 / 57(26.3 \%)$ & \\
\hline \multicolumn{4}{|c|}{ Likelihood of having mental disorder (based on K10 score ${ }^{\xi}$ ) } \\
\hline Likely to be well (K10 score 10-19) & $151(72.6 \%)$ & $66(77.6 \%)$ & 0.52 \\
\hline $\begin{array}{l}\text { Likely to have } \mathrm{mild} / \text { moderate disorder } \\
\text { (K10 score 20-29) }\end{array}$ & $40(19.2 \%)$ & $15(17.6 \%)$ & \\
\hline $\begin{array}{l}\text { Likely to have severe disorder } \\
\text { (K10 score 30-50) }\end{array}$ & $17(8.2 \%)$ & $4(4.7 \%)$ & \\
\hline \multicolumn{4}{|l|}{ Chronic health conditions } \\
\hline Diabetes & $28(13.5 \%)$ & $35(41.2 \%)$ & $<0.001$ \\
\hline Heart disease & $22(10.6 \%)$ & $26(30.6 \%)$ & $<0.001$ \\
\hline High blood pressure & $47(22.6 \%)$ & $42(49.4 \%)$ & $<0.001$ \\
\hline \multicolumn{4}{|l|}{ Erectile dysfunction (based on IIEF score) } \\
\hline $\begin{array}{l}\text { Mild or mild-to-moderate erectile } \\
\text { dysfunction (IIEF score 13-24) }\end{array}$ & $27(13 \%)$ & $20(23.5 \%)$ & 0.01 \\
\hline $\begin{array}{l}\text { Moderate or severe erectile dysfunction } \\
\text { (IIEF score 1-12) }\end{array}$ & $25(12 \%)$ & $16(18.8 \%)$ & \\
\hline \multicolumn{4}{|l|}{ Self-assessed health status ${ }^{\natural}$} \\
\hline Fair/poor & $42(20.2 \%)$ & $26(30.6 \%)$ & 0.12 \\
\hline Good & $91(43.8 \%)$ & $36(42.4 \%)$ & \\
\hline Very good/excellent & $75(36 \%)$ & $23(27.1 \%)$ & \\
\hline
\end{tabular}

$\| \mathrm{EF}=$ International Index of Erectile Function. $\mathrm{K} 10=$ Kessler Psychological Distress Scale. * Unless specified otherwise. $†$ Eight men in the 18-44 years age group and one man in the 45-74 years age group had missing height or weight data and are not included in the BMI results. $¥$ One man in the 18-44 years age group did not answer this question and is not included in the results. $\$$ Based on categories of the K1O scores (minimum score $=10$, indicating no distress; maximum score $=50$, indicating severe distress). ${ }^{16}$ q Based on general health question from the 12-Item Short-Form Health Survey, ${ }^{17}$ with outcomes summarised into three categories.

adequate register of the population and random sampling was not feasible. ${ }^{14}$ A target of 80 men in each of four regions covering urban, rural and remote areas $(n=320)$ would have sufficient power to detect a difference of six percentage points between this study and one of the general Australian population ${ }^{3}$ on a measure of ED. The inclusion criteria were being aged at least 18 years, living in a target community, being able to give signed informed consent, and not being acutely unwell or affected by drugs or 
alcohol at the time of completing the questionnaire. Two male Aboriginal researchers helped participants who were unable to read or understand the questionnaire.

\section{Data collection}

Quantitative data: The questionnaire included questions about demographics, chronic diseases, risk factors, mental health and wellbeing, and sexual and reproductive health. Questionnaires were completed during individual, confidential interviews over 12 months between 1 May 2004 and 30 April 2005. The interviews took place where participants felt most comfortable, confident and secure. Information was treated in a confidential, secure and respectful manner.

Qualitative data: Interviews and focus groups were tape-recorded and transcribed for thematic analysis with quotes presented to highlight the questionnaire findings.

Measures: Data were self-reported using validated tools where possible. The erectile function subscale (score range from 1 to 30) of the International Index of Erectile Function $(\text { IIEF })^{15}$ was used to measure the level of ED. Moderate-to-severe ED included scores of 1 to 12 , mild or mild-to-moderate ED included scores of 13 to 24 , and scores of 25 to 30 indicated no ED.

\section{Statistical analysis}

We used $\chi^{2}$ tests to determine the strength of evidence for possible associations between demographics, lifestyle, and health factors and age group. To assess possible determinants of ED, demographic and health variables showing bivariable associations with moderate-to-severe ED (versus no ED, or mild or mild-to-moderate ED, not shown in boxes) were tested in age-adjusted logistic regression models. Age-adjusted associations significant at $P<0.10$ were included in multivariable models.

We compared questions on helpseeking related to reproductive health with identical questions used in the Men in Australia Telephone Survey (MATeS) study, a national survey of a representative sample of Australian men aged 40 years or over. ${ }^{3}$ As the present study had a much younger age distribution compared with
3 Prevalence of mild and moderate-to-severe erectile dysfunction according to age group in 293 Aboriginal and Torres Strait Islander men

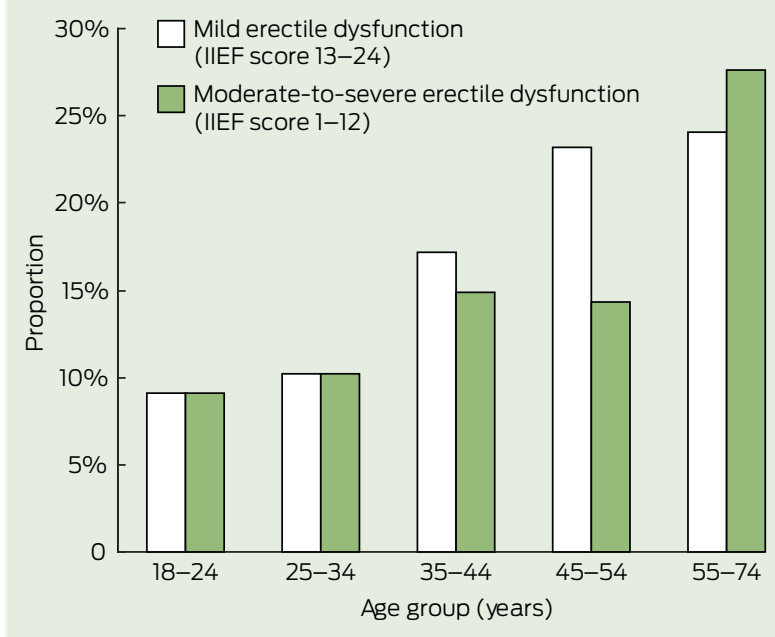

IIEF = International Index of Erectile Function.

MATeS, only men aged 40 to 59 years from each study were included to allow adequate numbers for meaningful comparisons.

\section{Results}

Participants included 293 men from townships and communities in Dar-

\begin{tabular}{|c|c|c|c|c|c|c|}
\hline Variables & Age-adjusted $^{\dagger}$ OR & $95 \% \mathrm{Cl}$ & $P$ & Fully adjusted $^{\dagger} \mathrm{OR}$ & $95 \% \mathrm{Cl}$ & $P$ \\
\hline Location & & & $<0.001$ & & & 0.02 \\
\hline Urban (reference category) & - & - & & - & - & \\
\hline Rural & 0.50 & $0.11-2.25$ & & 0.44 & $0.09-2.25$ & \\
\hline Remote & 4.86 & $2.28-10.35$ & & 2.94 & $1.17-7.38$ & \\
\hline Education level & & & 0.007 & & & 0.12 \\
\hline Primary & 8.83 & $2.30-33.90$ & & 5.80 & $1.09-30.89$ & \\
\hline Secondary & 4.77 & $1.38-16.51$ & & 4.23 & $0.90-19.85$ & \\
\hline Tertiary (reference category) & - & & & - & & \\
\hline Marital status & & & 0.001 & & & 0.05 \\
\hline Married/partnered (reference category) & - & & & - & & \\
\hline Separated/divorced & 4.06 & $1.55-10.61$ & & 3.09 & $1.07-8.90$ & \\
\hline Single & 3.73 & $1.64-8.48$ & & 2.44 & $0.95-6.26$ & \\
\hline Employment status & & & 0.003 & & & 0.19 \\
\hline Employed (reference category) & - & & & - & & \\
\hline Unemployed & 2.37 & $1.01-5.54$ & & 0.95 & $0.35-2.58$ & \\
\hline Pensioner & 5.56 & $2.22-13.90$ & & 2.19 & $0.74-6.47$ & \\
\hline Student & 2.67 & $0.51-13.95$ & & 5.84 & $0.74-45.84$ & \\
\hline Chronic condition ${ }^{\ddagger}$ & & & $<0.001$ & & & 0.005 \\
\hline $\begin{array}{l}\text { No self-reported diabetes, heart disease or high } \\
\text { blood pressure (reference category) }\end{array}$ & - & & & - & & \\
\hline $\begin{array}{l}\text { Self-reported diabetes, heart disease or high } \\
\text { blood pressure }\end{array}$ & 4.36 & $1.94-9.77$ & & 3.67 & $1.49-9.05$ & \\
\hline
\end{tabular}

$\mathrm{OR}=$ odds ratio. * Nagelkerke’s $R^{2}=0.33$ for full model. $†$ Age (continuous variable) included in all models. $\ddagger$ Self-reported diabetes, heart disease and high blood pressure were highly correlated and combined into a single variable with two categories: presence of one or more of the three chronic conditions

versus absence of all three conditions. 
win (urban) in the Northern Territory; the Tiwi Islands (remote); Cairns (urban) and Yarrabah (remote) in northern Queensland; and Brisbane (urban), Caloundra (rural) and Hervey Bay (rural) in southern Queensland. Most men lived in urban areas and had Aboriginal ancestry (Box 1). The majority $(71 \%)$ were younger than 45 years of age, about one-quarter had a tertiary qualification, and just over $60 \%$ were employed.

Box 2 shows a high prevalence of overweight and obesity, which was more frequent in older men, as were self-reported diagnoses of diabetes, heart disease and high blood pressure. Smoking and drinking alcohol were associated with younger age. Prostate problems were reported by four men and prostate cancer by two (not shown in boxes).

\section{Erectile dysfunction}

Overall, $16 \%$ of men had mild or mild-to-moderate ED, and $14 \%$ had moderate-to-severe ED with significantly higher prevalence across age groups (Box 2 and Box 3 ).

All variables showing bivariable associations with ED (listed in Box 4) remained associated with ED after adjusting for age. In the fully adjusted model, there is moderately strong evidence of association of moderate-tosevere ED with residence in a remote area (odds ratio [OR], 2.9; $P=0.02$ ) and having a chronic condition (OR, 3.7; $P=0.005)$, and weak evidence of association of ED with not being married or partnered.

\section{Help-seeking behaviour compared with that of non-Indigenous Australian men}

Box 5 compares help-seeking behaviour related to reproductive health in men aged 40 to 59 years from this study with that of similarly aged men from the MATeS study. ${ }^{3}$ The data for men in this study are broadly comparable to the data on Aboriginal and Torres Strait Islander men in the MATeS study. The much larger sample of non-Indigenous men from the MATeS study showed similar proportions to the present sample for attending a doctor in the preceding year for a general check-up or for erectile problems (ever) in each group. However, blood tests for prostate problems and digital rectal examinations were more commonly reported in non-Indigenous men. More than $60 \%$ of each group expressed concern about prostate cancer.

\section{Barriers to help-seeking for reproductive health disorders}

Findings from the focus groups and interviews revealed that Aboriginal and Torres Strait Islander males often keep silent about reproductive health (Box 6). While some participants were aware of some risk factors for ED, they believed that little education was available. Neither the men who participated in the focus groups and interviews nor their partners had a full understanding of ED, potentially creating tension and conflict. Feelings of shame (embarrassment) and low self-esteem were expressed, further contributing to communication difficulties.

Problems in communicating about ED were seen to be related to men speaking only in a roundabout way when discussing sexual matters among themselves, or waiting for the worst-case scenario before talking to their wives or partners. Difficulties with talking to health professionals related to fear of lack of confidentiality within the community and stigma attached to sexual problems.

The lack of culturally appropriate health services for males was highlighted as a barrier for men with reproductive problems - specifically, the predominance of female health professionals, and health workers and services not encompassing cultural aspects of family and gender.

\section{Discussion}

This study, the first to address reproductive health disorders in Aboriginal and Torres Strait Islander men, confirms that high rates of chronic disease coexist with reproductive health problems. ${ }^{7}$ Significant numbers of Aboriginal and Torres Strait Islander men, including younger men, reported erectile problems and, as seen in other population studies, 3,11 prevalence increased with age. The earlier onset of chronic disease in Aboriginal and Torres Strait Islander men $^{6}$ may explain the rates of ED among younger men, and provide opportunities for early identification of more serious conditions. Diabetes,

\begin{tabular}{|c|c|c|c|c|}
\hline & $\begin{array}{l}\text { Aboriginal and Torres } \\
\text { Strait Islander men aged } \\
40-59 \text { years }\left(n=123^{*}\right)\end{array}$ & $\begin{array}{l}\text { Aboriginal and Torres Strait } \\
\text { Islander men aged 40-59 } \\
\text { years from MATeS }\left(n=41^{*}\right)\end{array}$ & $\begin{array}{l}\text { Non-Indigenous men } \\
\text { aged } 40-59 \text { years } \\
\text { MATeS }\left(n=3124^{*}\right)\end{array}$ & $P^{\dagger}$ \\
\hline Had check-up with doctor in past year & $101 / 123(82.1 \%)$ & $34 / 41(82.9 \%)$ & $2606 / 3120(83.5 \%)$ & 0.70 \\
\hline Ever seen doctor for erectile problems & $11 / 120(9.2 \%)$ & 0 & 259/3095 (8.4\%) & 0.80 \\
\hline $\begin{array}{l}\text { Had treatment for erectile problems (proportion of } \\
\text { those who reported seeing a doctor for erectile } \\
\text { problems) }\end{array}$ & $7 / 11(63.6 \%)$ & 0 & $148 / 259(57.1 \%)$ & 0.67 \\
\hline Ever used drugs for sexual performance & $13 / 123(10.6 \%)$ & $-^{\ddagger}$ & $110(3.5 \%)$ & $<0.001$ \\
\hline Ever told you have a prostate problem & 0 & 0 & $160(5.1 \%)$ & na \\
\hline Ever had blood test for prostate problem & $14 / 123(11.4 \%)$ & $6 / 41(14.6 \%)$ & $1065(34.1 \%)$ & $<0.001$ \\
\hline Ever had a digital rectal examination & $12 / 118(10.2 \%)$ & $8 / 41(19.5 \%)$ & $1181 / 3117(37.9 \%)$ & $<0.001$ \\
\hline Had diagnosis of prostate cancer & $1(0.8 \%)$ & $0(0 \%)$ & $17(0.5 \%)$ & $0.50^{\wp}$ \\
\hline Moderately or very concerned about prostate cancer & $70 / 114(61.4 \%)$ & $23 / 40(57.5 \%)$ & $1952 / 3110(62.8 \%)$ & 0.21 \\
\hline
\end{tabular}

Moderately or very concerned about prostate cance

$23 / 40(57.5 \%)$

$1952 / 3110(62.8 \%)$

MATeS = Men in Australia Telephone Survey. na = not applicable. $*$ Denominators vary slightly because of missing data for some questions. $\dagger P$ values refer to comparisons between the 123 men from the present study and the 3124 non-Aboriginal men from the MATeS study. Data for the small number of Aboriginal and Torres Strait Islander men from the MATeS study are included for information only. $¥$ Question not answered by this group. $\S$ Fisher exact test. 
heart disease and high blood pressure were all frequently reported by the men in this study, and moderate-tosevere ED was strongly associated with having one or more of these conditions in the multivariable model. The implications of a diagnosis of ED for future cardiovascular disease, ${ }^{1,18,19}$ as well as the effect of ED on quality of life, ${ }^{20}$ make it imperative that men are able to access appropriate care and treatment. However, this study highlights the low rate of men seeking help for ED.

The study provides insight into the barriers to seeking help for reproductive disorders in Aboriginal and Torres Strait Islander communities and may point to ways of improving access to health services. ${ }^{7}$ Living in remote or regional areas or having a non-English-speaking background are barriers to help-seeking for men in the general population ${ }^{3}$ and may also be important for Aboriginal and Torres Strait Islander men. The qualitative data suggest that issues including shame, lack of appropriate people to talk to, and lack of knowledge about reproductive conditions may also be barriers. A lack of culturally appropriate health services has previously been recognised as a problem for Aboriginal and Torres Strait Islander males. ${ }^{7}$

The lower rates of testing for prostate disease (blood test or digital rectal examination) among Aboriginal and Torres Strait Islanders compared with non-Indigenous men show that additional barriers may be operating, despite similar levels of concern and equivalent likelihood of visiting a doctor in the preceding year. A lack of gender-specific services with male health professionals ${ }^{7}$ may be a compounding factor. Further, the earlier onset of chronic health disorders may mean that prostate disease is not given high priority in health services. Cancer statistics show that Indigenous people are more likely to have cancer diagnosed at a later stage, less likely to receive adequate treatment and more likely to die from their cancer than other Australians, ${ }^{21,22}$ which is partly explained by the failure of health systems. ${ }^{22}$ Rates of prostate cancer testing among Aboriginal and Torres Strait Islander men are missing from existing cancer data, but the present study, albeit small, suggests that they would be low.

Population studies of male reproductive disorders ${ }^{3,11,12}$ have been limited by a lack of Aboriginal and Torres Strait Islander participants, caused by their low numbers relative to the general population and other cultural and logistic factors. This study shows the feasibility of incorporating cultural and ethical requirements for research in these communities, and that men will talk about sensitive health issues in a culturally safe environment. Importantly, the insider/outsider status of the lead researcher (MJA) was pivotal to the study - as an insider, by facilitating the study through cultural knowledge, family linkages and a long association with the Aboriginal communities, and as an outsider, having the background to establish a safe and secure environment that invited full participation of Aboriginal and Torres Strait Islander men, combined with appropriate research methods.

Limitations of the study include the non-representative sample, resulting from the recruitment of communities using the links of the lead author. Moreover, some measures used in this study, in particular the IIEF, have not been validated in Aboriginal and Torres Strait Islander populations. This may partly explain the association between ED and living in a remote area, not seen in other population-based studies. ${ }^{3}$ Given that men in this study may have been assisted with the questionnaire, the IIEF may be prone to greater over-reporting when literacy levels are lower (in remote areas $^{23}$ ) - a hypothesis for future investigation. The estimates of prevalence should therefore be considered with caution, although they are in the vicinity of those reported in other Australian studies. $3,11,24$

The paucity of studies in Aboriginal and Torres Strait Islander male reproductive health makes comparison of our findings to others difficult and highlights the need for further research. However, these preliminary findings provide valuable data on reproductive health disorders and the potential for interventions for these

6 Quotes from focus groups and interviews with 38 Aboriginal and Torres Strait Islander men illustrating key themes in barriers to seeking help for reproductive health disorders

Silence

"A lot of Aboriginal men sort of keep it to themselves." (AHW)

Awareness of some chronic disease risk factors but limited understanding of erectile dysfunction or treatment

"You've got diabetes and your blood flow isn't at its best, it can create that sort of thing." (CW)

"Many males actually hide behind the fact that there is a problem mainly because they do not understand about the availability of treatment." (FG)

Possibility of difficulties and conflict in relationships or accusations of unfaithfulness

"I think it would put a huge bloody strain on relationships." (CR)

\section{Difficulties in communication}

\section{Talking in roundabout ways}

"... oh I heard so and so has got this problem, do you think that'd be true ... are they talking about that or themselves. That's usually how you can tell if they're talking about problems." (CW)

Shame (embarrassment) and low self-esteem

"It's a shame thing with our people that they won't discuss sexual problems ... I think they shamed; they don't want to ruin their image, you know, by letting people know." (CR)

\section{Only talk when symptoms are bad}

"Well if it got really serious or a lot of pain or something or passing blood or something, I would tell my wife and maybe she'd probably talk me into going to the doctor's but unless there's really serious ..." (CR)

Concerns about confidentiality, stigma, privacy

"In a group of males we don't actually talk about sexual ability." (CR)

"I think that they would have difficulty in talking to even the male health worker because like, in this community, like when they see a male health worker going to talk to a man, they know and they start making fun of that man." (CW)

"I think it's all that stuff about the shame you're always worried someone is going to find out there is something wrong with you." (CR)

Lack of culturally appropriate health services for males

"... you're a bit scared to go into a female one and talk to a female about what's going on down there." (CR)

$\mathrm{AHW}=$ Aboriginal health worker. $\mathrm{CR}=$ community resident. $\mathrm{CW}=$ community worker

$F G=$ focus group. 
and other chronic health conditions. This study provides some insight into barriers to men accessing health services, but further studies are needed to inform culturally appropriate interventions to support men seeking health care, particularly for more sensitive health concerns.

Acknowledgements: We wish to thank all the men who participated in the research, and the Aboriginal and Torres Strait Islander peoples for allowing us to undertake this research study in their communities. Without their support we would not have been able to collect the valuable information recorded here. Special mention must go to Carolyn Lang, Stanley John Ridgeway, Helen Hewett and Sue Naish for their patience and involvement. We also thank Damien Jolley for his statistical advice. Andrology Australia is supported by the Australian Government Department of Health and Ageing.

Competing interests: Andrology Australia has received financial support from Pfizer for a men's health education workshop for practice nurses, from Bayer and Eli Lilly for a men's health advisory forum, and from Janssen-Cilag for a general practitioner education workshop.

Received 14 Mar 2012, accepted 27 Sep 2012

1 Holden CA, Allan CA, McLachlan RI. Windows of opportunity: a holistic approach to men's health. Med J Aust 2010; 192: 708-711.

2 Thompson IM, Tangen CM, Goodman PJ, et al. Erectile dysfunction and subsequent cardiovascular disease. JAMA 2005; 294: 2996-3002.

3 Holden CA, McLachlan RI, Pitts M, et al. Men in Australia Telephone Survey (MATeS): a national survey of the reproductive health and concerns of middle-aged and older Australian men. Lancet 2005; 366: 218-224

4 Holden CA, Jolley DJ, McLachlan RI, et al. Men in Australia Telephone Survey (MATeS): predictors of men's help-seeking behaviour for reproductive health disorders. Med J Aust 2006; 185: 418-422.
5 Warr D, Hillier L. 'That's the problem with living in a small town': privacy and sexual health issues for young rural people. Aust J Rural Health 1997; 5 : 132-139.

6 Australian Institute of Health and Welfare. The health and welfare of Australia's Aboriginal and Torres Strait Islander people: an overview 2011. Canberra: AlHW, 2011. (AlHW Cat. No. IHW 42.) http://www.aihw.gov.au/publication-detail/?id= 10737418989 (accessed Oct 2012).

7 Wenitong M. Indigenous male health: a report for Indigenous males, their families and communities, and those committed to improving Indigenous male health. Canberra: Department of Health and Ageing, 2002

8 Jackson G, Boon N, Eardley I, et al. Erectile dysfunction and coronary artery disease prediction: evidence-based guidance and consensus. Int J Clin Pract 2010; 64: 848-857.

9 National Health and Medical Research Council. Values and ethics - guidelines for ethical conduct in Aboriginal and Torres Strait Islander health research. Canberra: NHMRC, 2003. http:// www.nhmrc.gov.au/guidelines/publications/e52 accessed Oct 2012)

10 Feldman HA, Goldstein I, Hatzichristou DG, et al Impotence and its medical and psychosocial correlates: results of the Massachusetts Male Aging Study. J Urol 1994; 151: 54-61.

11 Richters J, Grulich AE, de Visser RO, et al. Sex in Australia: sexual difficulties in a representative sample of adults. Aust N Z J Public Health 2003; 27: 164-170.

12 Martin SA, Haren MT, Middleton SM, Wittert GA; Members of the Florey Adelaide Male Ageing Study (FAMAS). The Florey Adelaide Male Ageing Study (FAMAS): design, procedures \& participants. BMC Public Health 2007; 7: 126.

13 Adams M, de Kretser D, Holden C. Male sexual and reproductive health among the Aboriginal and Torres Strait Islander population. Rural Remote Health 2003; 3: 153.

14 Dunne MP. Sampling considerations. In Wiederman MW, Whitley BE Jr, editors.
Handbook for conducting research on human sexuality. Mahwah, $\mathrm{NJ}$ : Lawrence Erlbaum Associates, 2002: 85-112.

15 Rosen RC, Riley A, Wagner G, et al. The International Index of Erectile Function (IIEF): a multidimensional scale for assessment of erectile dysfunction. Urology 1997; 49: 822-830.

16 Andrews G, Slade T. Interpreting scores on the Kessler Psychological Distress Scale (K10). Aust N Z J Public Health 2001: 25: 494-497.

17 Ware J Jr, Kosinski M, Keller SD. A 12-Item ShortForm Health Survey: construction of scales and preliminary tests of reliability and validity. Med Care 1996; 34: 220-233.

18 Inman BA, Sauver لJ, Jacobson DJ, et al. A population-based, longitudinal study of erectile dysfunction and future coronary artery disease. Mayo Clin Proc 2009; 84: 108-113.

19 Chew K, Bremner A, Jamrozik K, et al. Male erectile dysfunction and cardiovascular disease: is there an intimate nexus? J Sex Med 2008; 5: 928-934.

20 Sand MS, Fisher W, Rosen R, et al. Erectile dysfunction and constructs of masculinity and quality of life in the multinational Men's Attitudes to Life Events and Sexuality (MALES) study. J Sex Med 2008; 5: 583-594.

21 Condon JR, Armstrong BK, Barnes A, Cunningham J. Cancer in Indigenous Australians: a review. Cancer Causes Control 2003; 14: 109-121.

22 Cunningham J, Rumbold AR, Zhang X, Condon JR. Incidence, aetiology, and outcomes of cancer in Indigenous peoples in Australia. Lancet Oncol 2008; 9: 585-595.

23 Australian Institute of Health and Welfare. A snapshot of men's health in regional and remote Australia. Canberra: AlHW, 2010. (AlHW Cat. No. PHE 120; Rural Health Series No. 11.) http:// www aihw govau/publication-detail/?id= 6442468343 (accessed Oct 2012).

24 Chew KK, Stuckey B, Bremner A, et al. Male erectile dysfunction: its prevalence in Western Australia and associated sociodemographic factors. J Sex Med 2008; 5: 60-69.

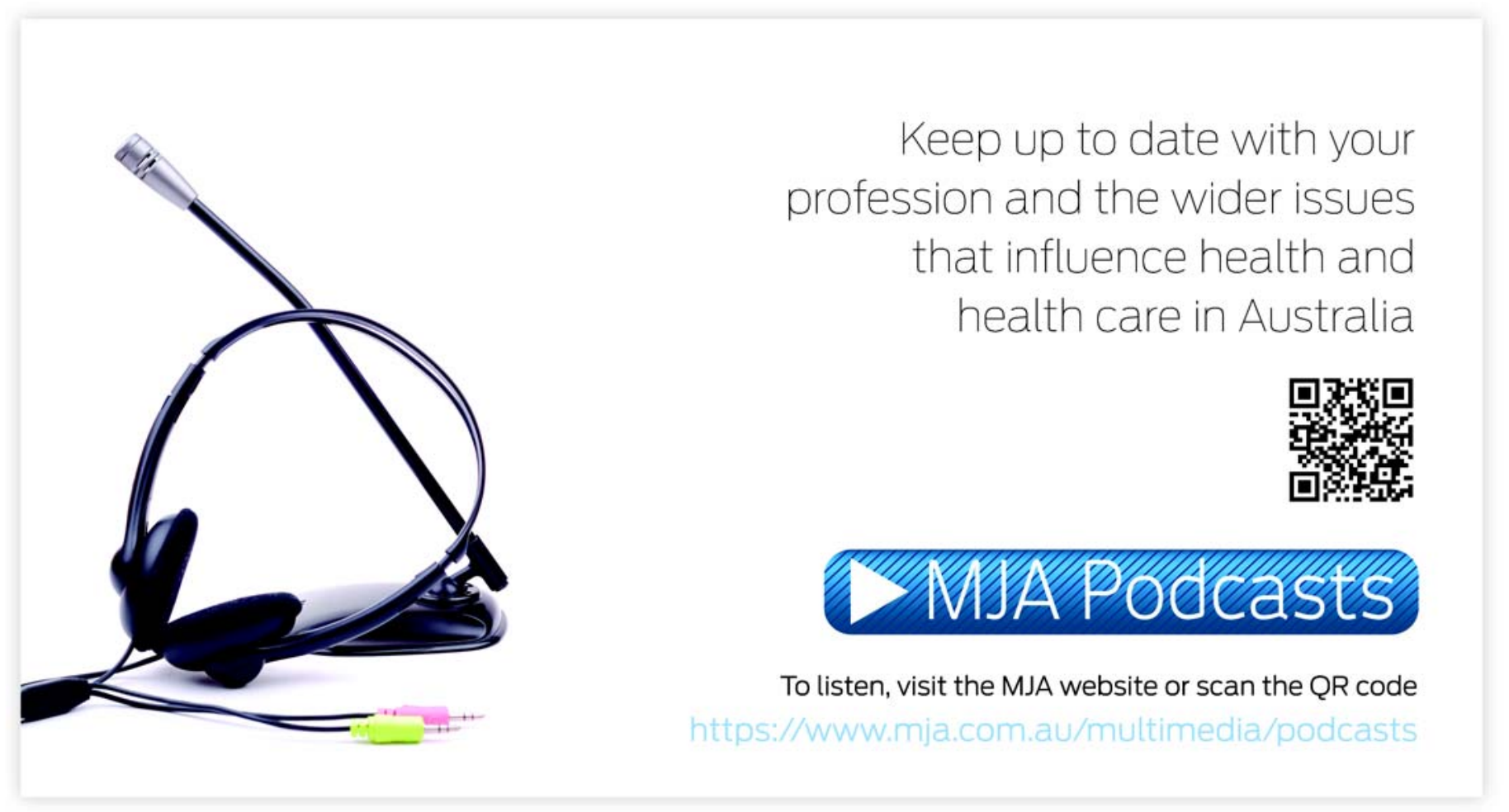

